\title{
The prognostic value of CXC chemokine receptor 2 (CXCR2) in cancers: a meta-analysis
}

\author{
Bingbing Qiao ${ }^{1, *}$, Wenqin Luo ${ }^{2, *}$, Yanna Liu', ${ }^{2,}$, Jing Wang ${ }^{3, *}$, Chuan Liu ${ }^{2}$, Zhao Liu ${ }^{2}$, \\ Sizhe Chen ${ }^{2}$, Jingjing $\mathbf{G u}^{2}$, Xiaolong $\mathbf{Q i}^{3}$ and Tongwei $\mathbf{W u}^{2,3}$ \\ ${ }^{1}$ Department of Hepatobiliary Surgery, The First Affiliated Hospital of Zhengzhou University, Zhengzhou, China \\ ${ }^{2}$ Department of General Surgery, Nanfang Hospital, Southern Medical University, Guangzhou, China \\ ${ }^{3}$ Department of Hepatobiliary Disease, The Affiliated (T.C.M) Hospital of Southwest Medical University, Luzhou, China \\ *These authors contributed equally to this work \\ \# Co-first author \\ Correspondence to: Bingbing Qiao, email: popzxcbb@163.com \\ Tongwei Wu, email: $445759131 @$ qq.com
}

Keywords: CXCR2; cancer; overall survival; recurrence-free survival; prognostic

Received: February 07, 2017 Accepted: September 03, 2017 Epub: December 11, 2017 Published: March 13, 2018

Copyright: Qiao et al. This is an open-access article distributed under the terms of the Creative Commons Attribution License 3.0 (CC BY 3.0), which permits unrestricted use, distribution, and reproduction in any medium, provided the original author and source are credited.

\section{ABSTRACT}

Background \& Aims: Quite a few studies had investigated the correlation between CXC chemokine receptor 2 (CXCR2) and cancer. This meta-analysis was aimed to comprehensively summarize the previous studies and to explore the prognostic value of CXCR2 in patients with cancer.

Materials and Methods: An adequate literature search in EMBASE and PubMed was conducted. Articles in English which have reported CXCR2 expression in patients and enough data to calculate hazard ratio (HR) were included. Effect estimates were analyzed with Review Manager 5.2. The endpoint was overall survival (OS) and recurrence-free survival (RFS).

Result: Twelve studies from 10 publications with a total of 2,461 patients were identified. It was shown that high level of CXCR2 was significantly associated with poorer overall survival (OS) (HR = 1.69, 95\% CI $\left.=1.46-1.96, p<0.0001, I^{2}=45 \%\right)$ and RFS (HR $\left.=1.50,95 \% \mathrm{CI}=1.25-1.80, p<0.0001, \mathrm{I}^{2}=6 \%\right)$. The analyses of different analysis models (univariate or multivariate models), sample size $(<\mathbf{3 0 0}$ or $\geq 300$ ) and ethnicity (Asian and Caucasian) have indicated the negative impact of CXCR2 over-expression on survival of patients with cancer. Stratified by cancer type, high-expression of CXCR2 was associated with unfavorable OS in laryngeal squamous cell carcinoma, lung cancer, pancreatic ductal carcinoma, clear-cell renal cell carcinoma and hepatocellular carcinoma; however, there was significant difference between high- and low-expression of CXCR2 in digestive tract cancer (esophageal adenocarcinoma and squamous cell carcinoma procession, resected esophageal carcinoma, esophageal cancer and gastric cancer).

Conclusions: CXCR2 is an unfavorable predictor in terms of OS and RFS in patients with cancer except for digestive tract cancer and is related with poorer prognostic.

\section{INTRODUCTION}

Cancer is the leading cause of death in both developing and developed countries. Meanwhile, both incidence and mortality of cancer grow rapidly for increasing population, senility, and unhealthy adoption of lifestyle behaviors [1]. It is identified that surgery, radiotherapy and chemotherapy are utilized as standard treatments in cancer cases. Nevertheless, most patients still have poor prognostic.

Chemokines, a large family of small and structurally related protein molecules with well-recognized roles 
in directional recruitment and migration of cells [2], have been implicated in migration of leukocytes, embryogenesis, angiogenesis, hematopoiesis, atherosclerosis, tumor growth and metastasis. There are four subgroups of chemokines: CXC, CC, CX3C, and $\mathrm{C}$ chemokine ligands. $\mathrm{CXC}$ chemokines are further subdivided into ELR + CXC chemokines and ELR - CXC chemokines.

CXC chemokine receptor 2 (CXCR2), an ELR $+\mathrm{CXC}$ chemokine receptor, was responsible for the angiogenic activity and endothelial cell chemotaxis [3]. Besides, CXCR2, also a receptor for IL-8, can regulate neutrophil migration to sites of inflammation [4]. Due to its role in recruiting myeloid cells to the tumor microenvironment and to the metastatic niche, CXCR2 may be engaged in tumorigenesis and the metastatic process [5]. In addition, previous studies have demonstrated that CXCR2 plays a critical role in cancers, such as lung cancer [6, 7], laryngeal squamous cell carcinoma [8], astrocytic tumors [9], pancreatic ductal carcinoma [10], clear-cell renal cell carcinoma [11] and hepatocellular carcinoma [12]. An et al. 2015 [11], had indicated that CXCR2 was correlated with poor prognosis and could be used as a novel prognostic factor in patients with non-metastatic clear-cell renal cell carcinoma (ccRCC). Moreover, Hertzer et al. 2013, had pointed out that CXCR2 could be considered as a target for pancreatic cancer treatment [13]. Varied in tumor types, although previous studies have drawn such a general consensus, no meta-analysis was conducted to analyze the prognosis value in cancer comprehensively. Therefore, this study, aimed to summarize prominent studies and determine the clinical efficacy of CXCR2 in predicting the prognosis of cancer patients, was carried out.

\section{MATERIALS AND METHODS}

\section{Literature search strategy}

PubMed and EMBASE database were searched up to October 25th, 2016. The search strategy was "CXCR2 or interleukin-8 receptor 2" in combination with "cancer". All eligible studies were retrieved, and their reference lists were checked for additional relevant publications.

\section{Inclusion criteria}

Studies researching comparisons of CXCR2 expression in patients with different types of cancer were eligible for inclusion. Studies that met all the following criteria were included: (i) English articles; (ii) reporting CXCR2 expression in cancer patients; (iii) enough data on the expression of CXCR2 or overall survival (OS) or recurrence-free survival (RFS) to calculate hazard ratio (HR).

\section{Exclusion criteria}

The exclusion criteria were as follows: (i) not focusing on the expression of CXCR2 in cancer patients; (ii) ongoing studies; (iii) review articles.

\section{Data extraction}

As for each study, the following information was extracted: year of publication, country, ethnicity, number of patients, the percentage of male and tumor type. Data extraction and information on study design, outcomes were performed by two independent reviewers (Zhao $\mathrm{Y}$ and Luo $\mathrm{W}$ ) and disagreements were resolved by discussion and consensus with a third reviewer (Qi X).

\section{Statistical analysis}

The specify guidelines we followed for this metaanalysis was PRISMA. Effect estimates were analyzed with Review Manager 5.2. Dichotomous data were compared using HR. The HRs with their 95\% confidence interval (CI) $\mathrm{s}$ were directly obtained from the article or calculated by using previously published methods [14]. Forest plots were generated for graphical presentations, and heterogeneity among different studies was appraised by $\mathrm{I}^{2}$ estimates. Fixed-effects model was used to aggregate data if there were no statistical heterogeneity $(p>0.1$ or $\mathrm{I}^{2}<50 \%$ ) otherwise randomized-effects model was conducted. Publication reporting bias was visually evaluated using the funnel plot. The difference was significant when $p<0.05$.

\section{RESULTS}

\section{Literature search}

As shown in Figure 1, 1,408 initial articles that included our search terms were obtained. Of those, 986 of records were screened after duplicates removed. The rest 45 articles were retrieved for full-text review, from which 33 were excluded: 25 not focusing on the expression of CXCR2 in cancer patients and 8 without efficient data on the expression of CXCR2 or overall survival (OS) or recurrence-free survival (RFS) to calculate HR. Finally, 12 studies met the inclusion criteria and were included in qualitative synthesis.

\section{Characteristics of included studies}

The detailed characteristics of included studies were listed in Table 1. The studies were conducted in 5 countries ( 9 Asian cohorts and 3 Caucasian cohorts), and they were published between 2012 and 2016. Studies concerning 5 digestive tract cancer (1 esophageal 
Table 1: Characteristic of studies

\begin{tabular}{|c|c|c|c|c|c|c|c|c|}
\hline Study Name & Year & Country & Ethnicity & Patients (n) & Male (\%) & Outcome & Tumor & Analysis \\
\hline Han et al. & 2012 & China & Asian & 109 & $98.16 \%$ & OS & laryngeal squamous cell carcinoma & M \\
\hline Korkolopoulou et al. & 2012 & Greece & Caucasian & 120 & $76.70 \%$ & OS & Astrocytic Tumors & M \\
\hline Saintigny et al. & 2013 & Texas & Caucasian & 262 & $48.90 \%$ & OS & lung adenocarcinoma & M \\
\hline Gold et al. & 2014 & America & Caucasian & 370 & $50.30 \%$ & OS, RFS & Non-Small Cell Lung & M \\
\hline Liang et al. & 2014 & China & Asian & 159 & $50.31 \%$ & OS & $\begin{array}{l}\text { esophageal adenocarcinoma and squamous } \\
\text { cell carcinoma procession }\end{array}$ & M \\
\hline Sui et al. & 2014 & China & Asian & 95 & $82.10 \%$ & OS & resected esophageal carcinoma & $\mathrm{U}$ \\
\hline Wang et al. & 2014 & China & Asian & 161 & $53.42 \%$ & OS & pancreatic ductal carcinoma & M \\
\hline An et al. & 2015 & China & Asian & 375 & $71.20 \%$ & OS, RFS & clear-cell renal cell carcinoma & M \\
\hline Li et al. & 2015 & China & Asian & 259 & $87.25 \%$ & OS, RFS & hepatocellular carcinoma & M \\
\hline Nishi et al. & 2015 & Japan & Asian & 82 & $89.00 \%$ & OS, RFS & esophageal cancer & $\mathrm{U}$ \\
\hline Wang et al. & 2015 & China & Asian & 357 & $70.00 \%$ & OS & gastric cancer & M \\
\hline Yang et al. & 2016 & China & Asian & 112 & $66.96 \%$ & OS & gastric adenocarcinoma & M \\
\hline
\end{tabular}

adenocarcinoma and squamous cell carcinoma procession cohort [15], 1 resected esophageal carcinoma cohort [16], 1 esophageal cancer cohort and 2 gastric cancer cohorts $[17,18])$ occupied the largest proportion of cancer type among all primary literatures, followed by lung cancer $(n=2)[6,7]$, then laryngeal squamous cell carcinoma $(n=1)$ [8], astrocytic tumors $(n=1)$ [9], pancreatic ductal carcinoma $(n=1)$ [10], clear-cell renal cell carcinoma $(n=1)$ [11] and hepatocellular carcinoma $(n=1)$ [12]. All studies reported the OS while only four studies reported

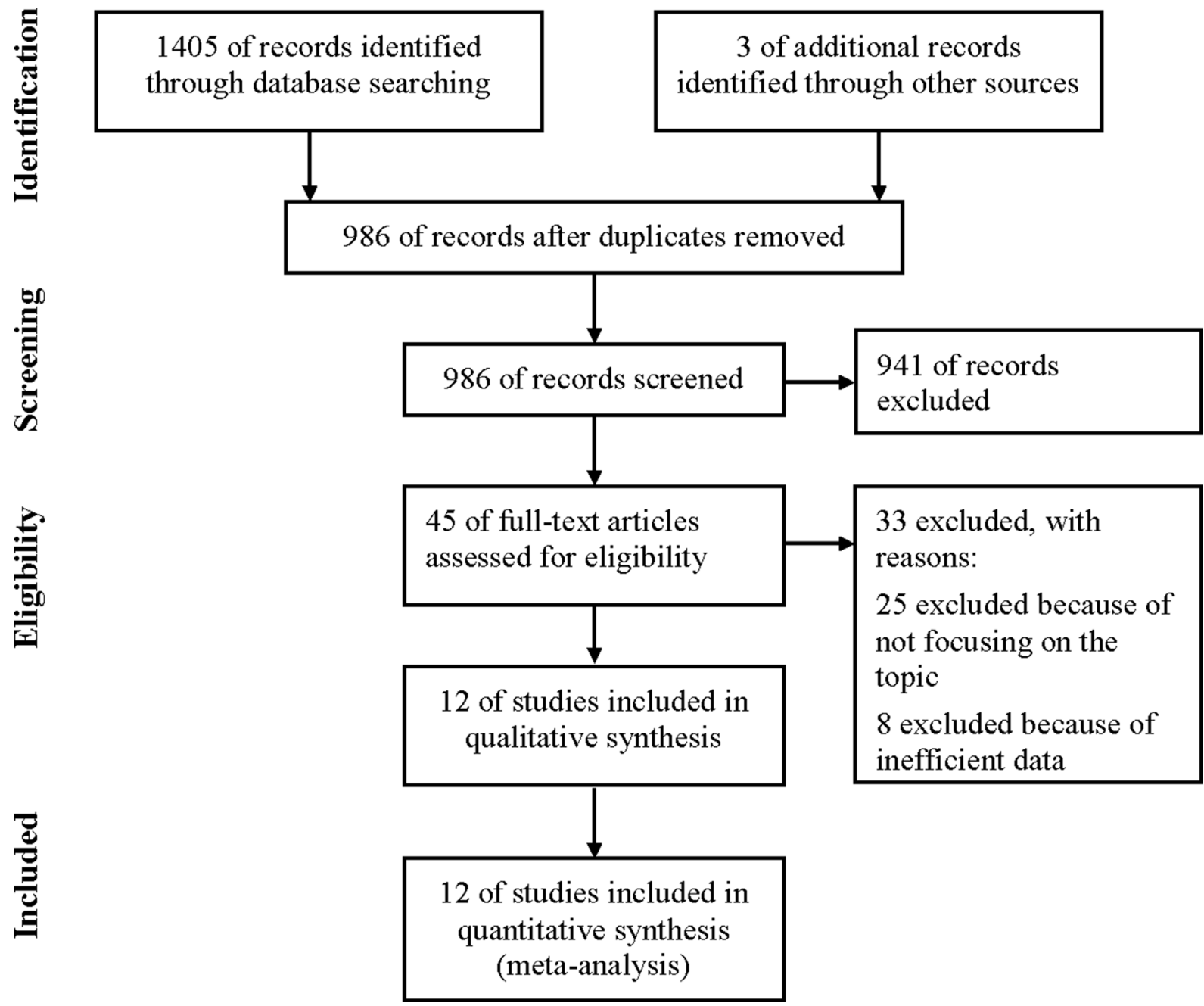

Figure 1: Flow diagram of study selection process. 
the RFS. Almost all the included studies used multivariate models except for two studies conducted by Sui et al. [16] and Nishi et al. [19], respectively, with univariate models.

\section{Study quality}

As presented in Table 2, the quality of each study included in this meta-analysis was graded with NewcastleOttawa scale, a score between 0-9 for each study (studies with score of 6-9 manifesting good quality studies). All studies included in this study had the score over 7, which indicated good quality.

\section{Meta-analyses of RFS}

Four eligible studies reported the RFS [7, 11, 12, 19, 20]. There was no significant heterogeneity between these studies when pooling the HR, so HR was pooled in the fixedeffects model. As Figure 2 shown, the results showed that higher expression of CXCR2 was correlated with shorten RFS $\left(\mathrm{HR}=1.50,95 \% \mathrm{CI}=1.25-1.80, p<0.0001 ; \mathrm{I}^{2}=6 \%\right.$, $p=0.36)$. Besides, there was no bias among all included studies from the funnel plot. (Supplementary Figure 1).

\section{Meta-analyses of OS}

As Figure 3 presented, twelve studies offered original data of OS. The synthesis showed that overexpression of CXCR2 was significantly related to a poorer OS $(\mathrm{HR}=1.69,95 \% \mathrm{CI}=1.46-1.96, p<0.0001)$. Because heterogeneity was detected $\left(\mathrm{I}^{2}=45 \%, p=0.04\right)$, a randomized-effects model was used to determine the pooled HR and 95\% CI. The funnel plot presented no bias among all included studies (Supplementary Figure 2).

As Table 3 shown, high-expression of CXCR2 was significantly related to a poorer OS for patients with laryngeal squamous cell carcinoma $(\mathrm{HR}=2.93,95 \% \mathrm{CI}$ $=1.10-7.75, p=0.03)$ in the subgroup analysis by tumor type, astrocytic tumors $(\mathrm{HR}=1.86,95 \% \mathrm{CI}=1.05-3.31$, $p=0.03)$, lung cancer $(\mathrm{HR}=1.56,95 \% \mathrm{CI}=1.22-2.01$, $\left.p=0.0005 ; \mathrm{I}^{2}=0 \%, p=0.98\right)$, pancreatic ductal carcinoma $(\mathrm{HR}=5.51,95 \% \mathrm{CI}=1.38-22.0, p=0.02)$, clear-cell renal cell carcinoma $(\mathrm{HR}=2.20,95 \% \mathrm{CI}=1.26-3.25$, $p=0.004)$ and hepatocellular carcinoma $(\mathrm{HR}=1.74,95 \%$ $\mathrm{CI}=1.17-2.59, p=0.007)$, respectively. However, highexpression of CXCR2 in digestive tract cancer $(\mathrm{HR}=$ $1.26,95 \% \mathrm{CI}=0.68-2.35, p=0.46 ; \mathrm{I}^{2}=73 \%, p=0.005$ ) has no effect on OS statistically.

Among the subgroup, two studies were demonstrated in univariate models ( $\mathrm{HR}=1.86,95 \% \mathrm{CI}=1.12-3.09, p=$ $\left.0.02 ; \mathrm{I}^{2}=0 \%, p=0.38\right)$ without heterogeneity, and ten in multivariate models $(\mathrm{HR}=1.66,95 \% \mathrm{CI}=1.30-2.14, p<$ $0.01 ; \mathrm{I}^{2}=53 \%, p=0.02$ ), with significant difference but with heterogeneity. With sensitivity analysis, the study by Liang et al. [15] was excluded with regard of OS analysis with multivariate models (Supplementary Figure 3). As shown in Figure 4, significant difference was detected between high- and low-expression of CXCR2 without heterogeneity in group with multivariate models $(\mathrm{HR}=$ $\left.1.78,95 \% \mathrm{CI}=1.52-2.08, p<0.01 ; \mathrm{I}^{2}=0 \%, p=0.76\right)$.

Besides, subgroup analyses by ethnicity revealed that CXCR2 was an unfavorable predictor of OS both in Asian populations along with a significant heterogeneity $\left(\mathrm{HR}=1.69,95 \% \mathrm{CI}=1.20-2.39, p=0.003 ; \mathrm{I}^{2}=59 \%, p\right.$ $=0.01)$, and in Caucasian populations $(\mathrm{HR}=1.61,95 \%$ $\left.\mathrm{CI}=1.28-2.02, p<0.00001 ; \mathrm{I}^{2}=0 \%, p=0.86\right)$ (Table 2). With sensitivity analysis, the study by Liang et al. [15] was excluded with regard of OS analysis in Asian group (Supplementary Figure 4). As shown in Figure 5, there was significant difference between high- and low-expression of CXCR2 without heterogeneity in Asian group $(\mathrm{HR}=1.93$, $\left.95 \% \mathrm{CI}=1.58-2.34, p<0.01 ; \mathrm{I}^{2}=0 \%, p=0.76\right)$.

Both in big sample size study (sample sizes $\geq 300$, $\mathrm{HR}=1.76,95 \% \mathrm{CI}=1.43-2.17, p<0.00001 ; \mathrm{I}^{2}=0 \%, p$ $=0.63$ ), and small sample size study (sample sizes $<300$, $\mathrm{HR}=1.61,95 \% \mathrm{CI}=1.13-2.32, p=0.009 ; \mathrm{I}^{2}=58 \%, p=$ 0.02 ) was consistently indicated that higher CXCR2 was correlated with shorten OS. But there was heterogeneity among the studies with small sample size (Table 2). Based on sensitivity presented in Supplementary Figure 5, study by Liang et al. [15] was excluded in analysis of small sample size group, the same as statistical analysis of Asian group. As what was shown in Figure 6, there was significant difference between high- and low-expression of CXCR2 without heterogeneity in small sample size group (HR = $\left.1.81,95 \% \mathrm{CI}=1.46-2.24, p<0.01 ; \mathrm{I}^{2}=0 \%, p=0.68\right)$.

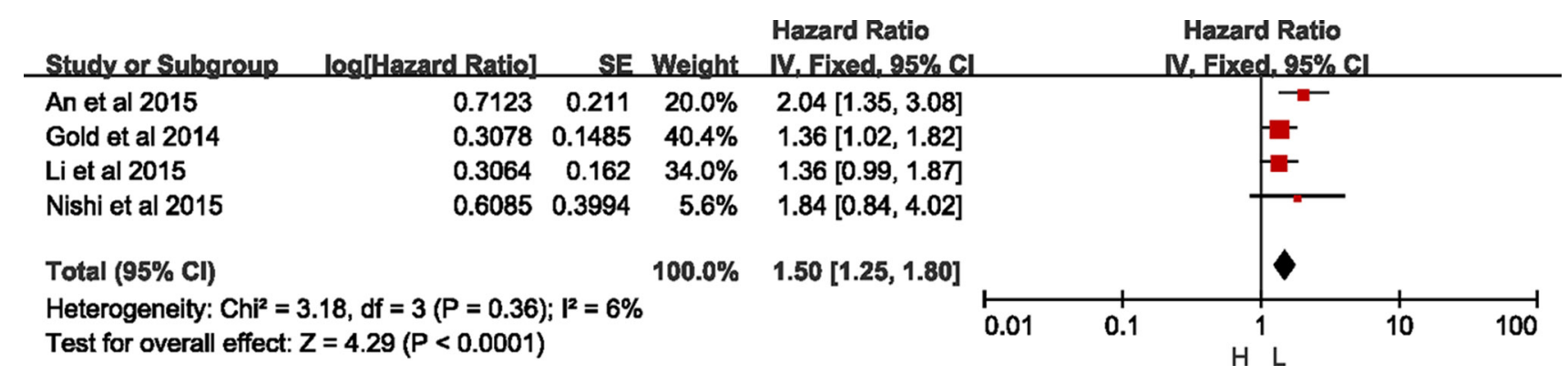

Figure 2: Meta-analysis of recurrence-free survival. 
Table 2: Quality indicators from the Newcastle-Ottawa scale

\begin{tabular}{|c|c|c|c|c|c|c|c|c|c|c|}
\hline \multirow{2}{*}{ Study } & \multicolumn{4}{|c|}{ Selection } & \multicolumn{2}{|c|}{ Comparable } & \multicolumn{3}{|c|}{ Outcome assessment } & \multirow[b]{2}{*}{ SCORE } \\
\hline & 1 & 2 & 3 & 4 & 1 & 2 & 1 & 2 & 3 & \\
\hline An et al. 2015 & $*$ & $*$ & $*$ & $*$ & $*$ & $*$ & $*$ & $*$ & $*$ & 9 \\
\hline Gold et al. 2014 & $*$ & $*$ & $*$ & * & $*$ & $*$ & $*$ & $*$ & & 8 \\
\hline Han et al. 2012 & $*$ & $*$ & $*$ & $*$ & $*$ & $*$ & $*$ & $*$ & & 8 \\
\hline Korkolopoulou et al. 2012 & $*$ & $*$ & $*$ & & $*$ & & $*$ & $*$ & * & 8 \\
\hline Li et al. 2015 & $*$ & $*$ & $*$ & $*$ & $*$ & $*$ & $*$ & $*$ & $*$ & 9 \\
\hline Liang et al. 2014 & $*$ & $*$ & $*$ & & $*$ & $*$ & $*$ & $*$ & & 7 \\
\hline Nishi et al. 2015 & $*$ & $*$ & $*$ & & $*$ & $*$ & $*$ & $*$ & $*$ & 8 \\
\hline Saintigny et al. 2013 & $*$ & $*$ & $*$ & & $*$ & $*$ & $*$ & $*$ & $*$ & 8 \\
\hline Sui et al. 2014 & $*$ & $*$ & $*$ & & $*$ & $*$ & $*$ & & $*$ & 7 \\
\hline Wang et al. 2014 & $*$ & $*$ & & $*$ & $*$ & $*$ & $*$ & $*$ & $*$ & 8 \\
\hline Wang et al. 2015 & $*$ & $*$ & & * & $*$ & $*$ & $*$ & $*$ & $*$ & 8 \\
\hline Yang et al. 2016 & $*$ & $*$ & $*$ & & $*$ & $*$ & $*$ & $*$ & & 7 \\
\hline
\end{tabular}

\section{DISCUSSION}

Cancer is still a large health problem worldwide. Although standard treatments have been utilized in most cancer patients, not all of patients derive benefit from these treatment strategies. It has been proven that low expression of CXCR2 was associated with increased tumor necrosis and the $\mathrm{CXC}$ chemokines receptors played a critical role in tumor either $[19,20]$.

Previous studies had demonstrated that chemokine interleukin-8 (CXCL8), the ligand of CXCR2, acted as autocrine and/or paracrine growth and proangiogenic factor for melanoma through CXCR2, inducing invasion and migration [21]. Study by $\mathrm{Ha}$ et al. reported that interaction between CXCL8 secreted by select cancer cells and CXCR2 in the tumor microenvironment is essential for cancer progression and metastasis by regulation cancer stem cell (CSC) proliferation and self-renewal
[22]. Moreover, it was covered that CXCR2 engaged in Rho, Rac and mitogen-activated protein kinase signaling pathways which were connected to cell growth and migration $[23,24]$.

In our meta-analysis, it was presented that high expression of CXCR2 was significantly related to shorten OS and was a risk factor of OS. Among the studies included in quantitative synthesis, the synthetic analysis of 4 eligible studies reported that high CXCR2 expression was correlated with shorten recurrence-free survival (RFS). It was also shown that high CXCR2 expression was a risk factor of RFS. Likewise, subgroup analyses revealed that $\mathrm{CXCR} 2$ was an unfavorable predictor of OS in cancer. The result that high-level of CXCR2 was a risk factor of both OS and PFS, consistent with previous finding, strengthened the fact that low expression of CXCR2 predicted better efficacy of cancer therapy. Furthermore, we expanded the discussion on the

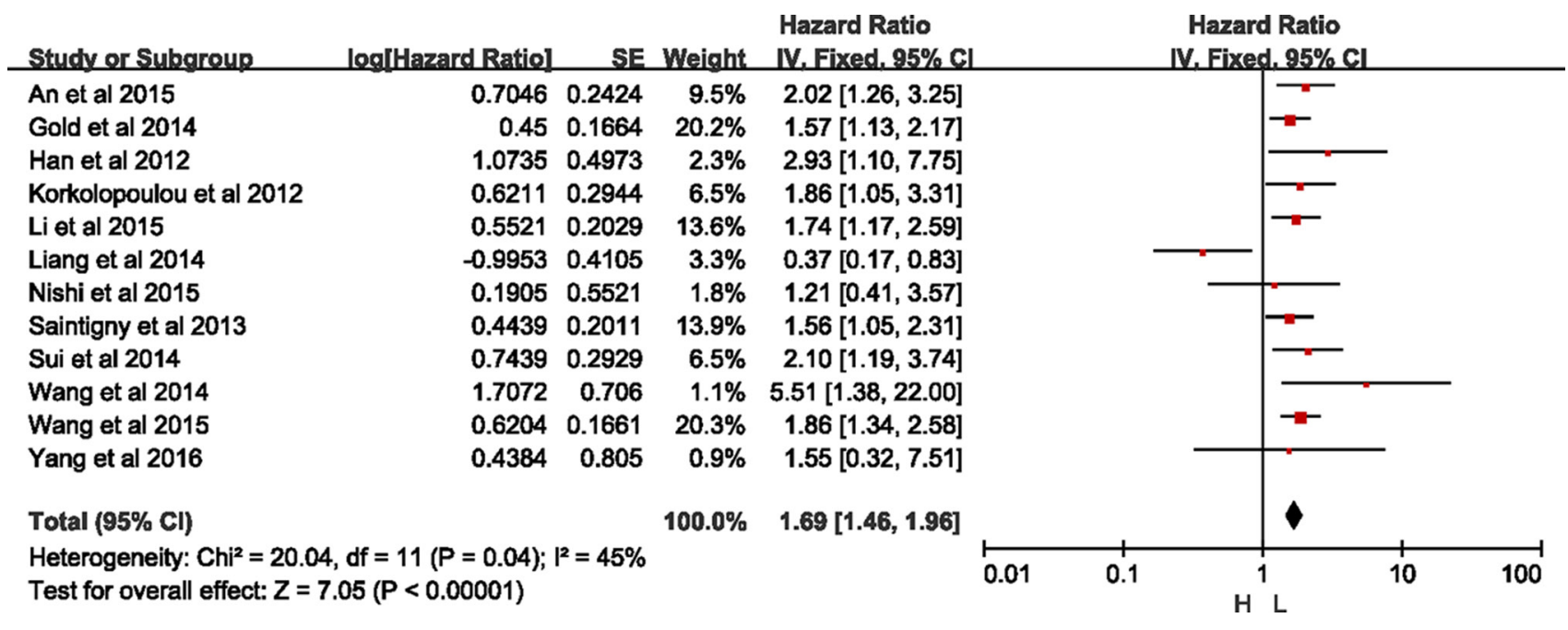

Figure 3: Meta-analysis of overall survival. 


\begin{tabular}{|c|c|c|c|c|c|}
\hline Survival analysis & Included cohorts & HR 95\% CI & $p$ & $\mathbf{I}^{2}$ & $\begin{array}{c}p \text { value for } \\
\text { heterogeneity }\end{array}$ \\
\hline \multicolumn{6}{|l|}{ Analysis model } \\
\hline Multivariate & 10 & $1.66[1.30,2.14]$ & $<0.00001$ & $53 \%$ & 0.02 \\
\hline Univariate & 2 & $1.86[1.12,3.09]$ & 0.02 & $0 \%$ & 0.38 \\
\hline \multicolumn{6}{|l|}{ Ethnicity } \\
\hline Caucasian & 3 & $1.61[1.28,2.02]$ & $<0.00001$ & $0 \%$ & 0.86 \\
\hline Asian & 9 & $1.69[1.20,2.39]$ & 0.003 & $59 \%$ & 0.01 \\
\hline \multicolumn{6}{|l|}{ Sample Size } \\
\hline$<300$ & 9 & $1.61[1.13,2.32]$ & 0.009 & $58 \%$ & 0.02 \\
\hline$\geq 300$ & 3 & $1.76[1.43,2.17]$ & $<0.00001$ & $0 \%$ & 0.63 \\
\hline \multicolumn{6}{|l|}{ Tumor } \\
\hline LSCC & 1 & $2.93[1.10,7.75]$ & 0.03 & NA & NA \\
\hline Astrocytic Tumors & 1 & $1.86[1.05,3.31]$ & 0.03 & NA & NA \\
\hline Lung cancer & 2 & $1.56[1.22,2.01]$ & 0.0005 & 0 & 0.98 \\
\hline $\mathrm{EACC} / \mathrm{ESCC} / \mathrm{ECC} / \mathrm{GC}$ & 5 & $1.26[0.68,2.35]$ & 0.46 & $73 \%$ & 0.005 \\
\hline PDAC & 1 & $5.51[1.38,22.0]$ & 0.02 & NA & NA \\
\hline $\mathrm{RCC}$ & 1 & $2.20[1.26,3.25]$ & 0.004 & NA & NA \\
\hline $\mathrm{HCC}$ & 1 & $1.74[1.17,2.59]$ & 0.007 & NA & NA \\
\hline
\end{tabular}

OS, overall survival; LSCC, laryngeal squamous cell carcinoma; EACC/ESCC, esophageal adenocarcinoma and squamous cell carcinoma procession; ECC, resected esophageal carcinoma; PDAC, pancreatic ductal carcinoma; RCC, clear-cell renal cell carcinoma; HCC, hepatocellular carcinoma; ESCC, esophageal cancer; GC, gastric cancer; NA, not applicable.

comprehensive influence of several cancers rather than concrete category of cancer; moreover, subgroup analysis based on different type of cancer was also conducted. It was identified that CXCR2 was a risk factor for cancer both in synthetic analysis and subgroup analysis. Moreover, it was suggested that overexpression of CXCR2 in liver metastases from colon cancer was correlated to short disease-free and OS in the study conducted by Desurmont et al. [25]. Besides, study by Rezakhaniha et al. reported that CXCR2 expressions were correlated with shorter OS [26]. However, one important caveat that needs to be considered was that only one study was included in the meta-analysis of laryngeal squamous cell carcinoma, astrocytic tumors, pancreatic ductal carcinoma, clear-cell renal cell carcinoma and hepatocellular carcinoma, respectively, which might influence the reliability and veracity of some subgroup analyses. In addition, the unfavorable prediction of CXCR2 was performed solidly in different analysis model, ethnicity and sample size, which suggested that CXCR2 was a powerful prognostic predictor with a wide application in general population. Overall, according to the result of our meta-

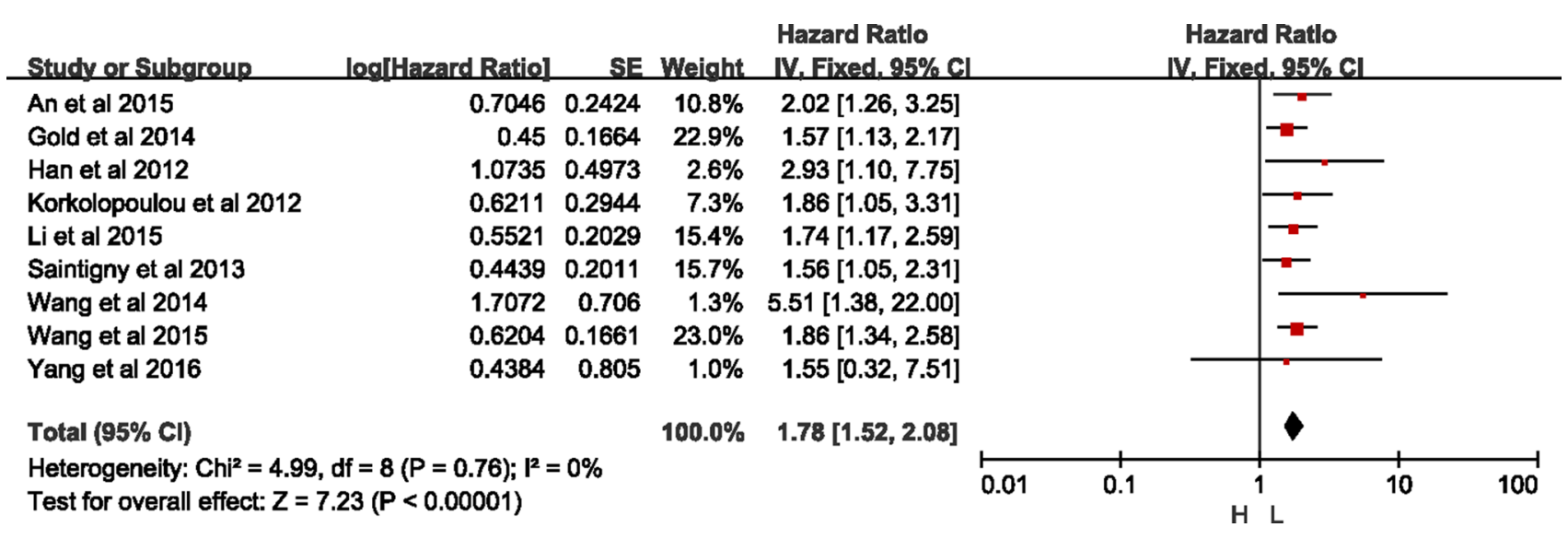

Figure 4: Meta-analysis of group with multivariate model. 
analysis, the better clinical management of cancer will be taken with the help of CXCR2 in the future. However, it was important to caveat that there was heterogeneity in subgroup analysis of Asian which indicated that the use of CXCR2 in Asian should be cautious. It was contradicted that study by Liang et al. [15] reported that overexpression of CXCR2 was a favorable prognosis predictor in Asian and study by Nishi et al. [19] and Yang et al. [28] reported that no significant difference was detected between high and low level of CXCR2 while the other studies conducted in Asian covered that overexpression of CXCR2 was a risk factor, which resulted the heterogeneity. Besides, the heterogeneity existed in small sample size studies might be located in the insufficient studies. Sensitivity analysis was conducted to detect the heterogeneity. In both subgroup analysis of groups with multivariate models, Asian group and small sample size with regard of OS, study by Liang et al. [15] was the source of heterogeneity, which reported that overexpression of CXCR2 was a favorable factor in esophageal adenocarcinoma and squamous cell carcinoma in terms of OS and was contradictory to previous studies.

The significant strength of our meta-analysis is that fully literature search was conducted and that no previous study illustrated the correlation between CXCR2 and cancers in the form of meta-analysis. Besides, the highlighted role of CXCR2 in several cancers was first explored synthetically in this meta-analysis. Moreover, several subgroup analysis were conducted to detect the influence of analysis models (univariate or multivariate models), sample size ( $<300$ or $\geq 300)$ and ethnicity (Asian and Caucasian) to the prognosis value of CXCR2. Besides, sensitivity was conducted to detect the heterogeneity exited in Asian group and small sample size group, and we found that the study by Liang et al. [15] was the source of heterogeneity. In this meta-analysis, it was first synthetically declared that CXCR2 was a potential and potent prognosis predictor in patients with cancer except for digestive tract cancer with wide application in clinic.

Nonetheless, our meta-analysis was not without limitations. For example, few studies were included to analyze RFS, which influenced the reliability of the results. Even if all 12 included studies have reported the OS, the number of relative study cohorts was still insufficient. Another 6 literatures [26-30] also presented the correlation between CXCR2 and OS, RFS, which all indicated that patients with lower CXCR2 expression had a better prognosis but without HR calculated in these studies. Moreover, the criteria to distinguish the expression

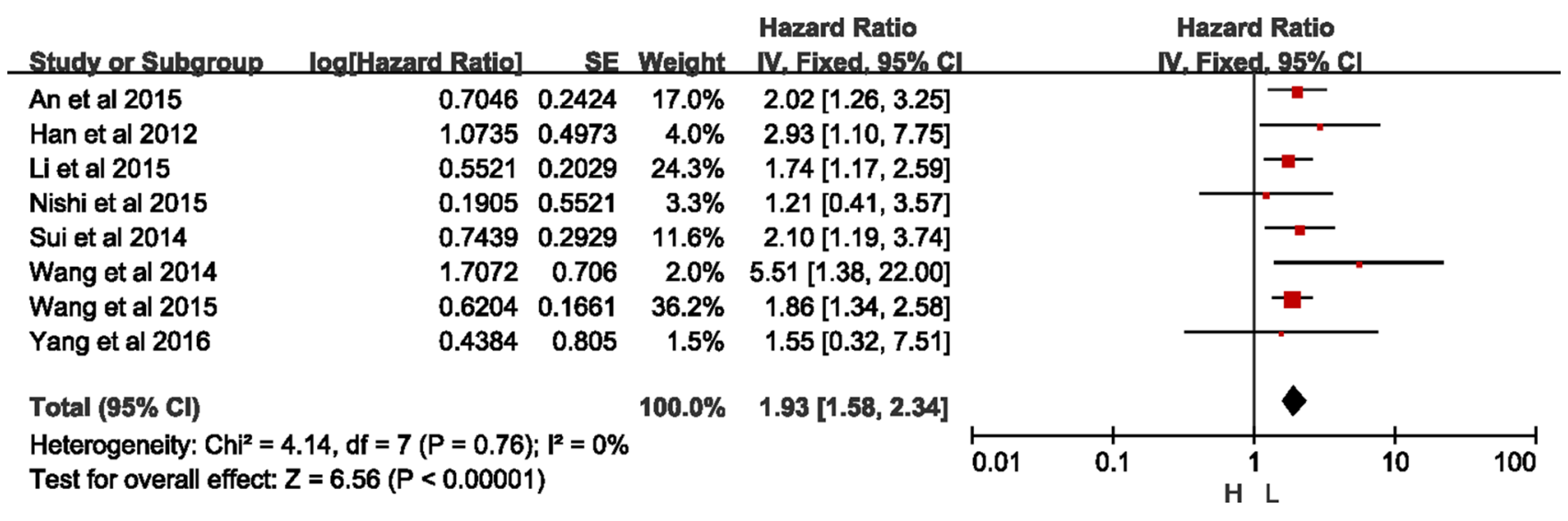

Figure 5: Meta-analysis of Asian group.

\begin{tabular}{|c|c|c|c|c|c|c|c|}
\hline Study or Subaroup & log[Harard Ratlo] & SE & Welght & $\begin{array}{l}\text { Hazard Ratio } \\
\text { IV,Flxed,95\% Cl }\end{array}$ & \multicolumn{2}{|c|}{$\begin{array}{c}\text { Hazard Ratio } \\
\text { W. Elxed, } 95 \% \text { Cl }\end{array}$} & \\
\hline Han et al 2012 & 1.0735 & 0.4973 & $4.9 \%$ & $2.93[1.10,7.75]$ & & & \\
\hline Korkolopoulou et al 2012 & 0.6211 & 0.2944 & $13.9 \%$ & $1.86[1.05,3.31]$ & & & \\
\hline Li өt al 2015 & 0.5521 & 0.2029 & $29.2 \%$ & $1.74[1.17,2.59]$ & & & \\
\hline Nishi et al 2015 & 0.1905 & 0.5521 & $3.9 \%$ & $1.21[0.41,3.57]$ & & & \\
\hline Saintigny et al 2013 & 0.4439 & 0.2011 & $29.8 \%$ & $1.56[1.05,2.31]$ & & & \\
\hline Sul et al 2014 & 0.7439 & 0.2929 & $14.0 \%$ & $2.10[1.19,3.74]$ & & & \\
\hline Wang et al 2014 & 1.7072 & 0.706 & $2.4 \%$ & $5.51[1.38,22.00]$ & & & \\
\hline Yang et al 2016 & 0.4384 & 0.805 & $1.9 \%$ & $1.55[0.32,7.51]$ & & & \\
\hline Total $(95 \% \mathrm{Cl})$ & & & $100.0 \%$ & $1.81[1.46,2.24]$ & & & \\
\hline $\begin{array}{l}\text { Heterogeneity: } \mathrm{Chi}^{2}=4.86 \\
\text { Test for overall effect: } \mathbf{Z}=\end{array}$ & $\begin{array}{l}\mathrm{df}=7(P=0.68) ; I^{2}= \\
41(P<0.00001)\end{array}$ & $0 \%$ & & 0.01 & 0.1 & 10 & 100 \\
\hline
\end{tabular}

Figure 6: Meta-analysis of small sample size group. 
level of CXCR2 were different in the enrolled studies, which might impair the veracity of the prognosis value of CXCR2. In addition, although there was unfavorable prognostic value of CXCR2 in digestive tract cancer in previous 4 studies [15-18] while the other one by Liang et al. [15] reported that CXCR2 indicates a better prognosis, in this meta-analysis, it was presented that no statistical significance was detected between high and low CXCR2 expression in subgroup analysis of digestive tract cancer in this meta-analysis. Hence, it was supposed that more clinical trials focused on the prognostic value of CXCR2 in digestive tract cancer should be conducted in the future. Last but not the least, patients in 7 studies included in this meta-analysis had no history of anticancer therapy while the others did not cover any concrete therapy. Although the conventional treatment of cancer might affect the expression of CXCR2, the analysis of conventional treatment were not conducted, which might affect the appliance of the results in this study.

In conclusion, CXCR2 was a risk factor of cancer prognosis with a wide application in terms of both OS and PFS except for digestive tract cancer, which could guide clinical treatment of various cancers. Further studies focused on more cancers especially for digestive tract cancer should be conducted.

\section{CONFLICTS OF INTEREST}

None.

\section{REFERENCES}

1. Torre LA, Siegel RL, Ward EM, Jemal A. Global Cancer Incidence and Mortality Rates and Trends--An Update. Cancer Epideiol Biomarkers Prev. 2016; 25:16-27.

2. Kulkarni N, Pathak M, Lal G. Role of chemokine receptors and intestinal epithelial cells in the mucosal inflammation and tolerance. J Leukoc Biol. 2017; 101:377-394.

3. Vandercappellen J, Van Damme J, Struyf S. The role of CXC chemokines and their receptors in cancer. Cancer Lett. 2008; 267:226-244.

4. Morton JP, Sansom OJ. CXCR2 inhibition in pancreatic cancer: opportunities for immunotherapy? Immunotherapy. 2017; 9:9-12.

5. Acharyya S, Oskarsson T, Vanharanta S, Malladi S, Kim J, Morris PG, Manova-Todorova K, Leversha M, Hogg N, Seshan VE, Norton L, Brogi E, Massague J. A CXCL1 paracrine network links cancer chemoresistance and metastasis. Cell. 2012; 150:165-178.

6. Saintigny P, Massarelli E, Lin S, Ahn YH, Chen Y, Goswami S, Erez B, O’Reilly MS, Liu D, Lee JJ, Zhang L, Ping Y, Behrens C, et al. CXCR2 Expression in Tumor Cells Is a Poor Prognostic Factor and Promotes Invasion and Metastasis in Lung Adenocarcinoma. Cancer Res. 2013; 73:571-582.
7. Gold KA, Kim ES, Liu DD, Yuan P, Behrens C, Solis LM, Kadara H, Rice DC, Wistuba II, Swisher SG, Hofstetter WL, Lee JJ, Hong WK. Prediction of Survival in Resected Non-Small Cell Lung Cancer Using a Protein Expression-Based Risk Model: Implications for Personalized Chemoprevention and Therapy. Clin Cancer Res. 2014; 20:1946-1954.

8. Han L, Jiang B, Wu H, Wang X, Tang X, Huang J, Zhu J. High expression of CXCR2 is associated with tumorigenesis, progression, and prognosis of laryngeal squamous cell carcinoma. Med Oncol. 2012; 29:2466-2472.

9. Korkolopoulou P, Levidou G, El-Habr EA, Adamopoulos C, Samaras V, Zisakis A, Kavantzas N, Boviatsis E, Fragkou P, Papavassiliou AG, Patsouris E, Piperi C. Expression of interleukin-8 receptor CXCR2 and suppressor of cytokine signaling-3 in astrocytic tumors. Mol Med. 2012; 18:379-88.

10. Wang Q, Zheng J, Ni Q, Zhu H, Lu Y, Qian H, Zhu J. Prognostic significance of CXCR2 expression in pancreatic ductal carcinoma. Natl Med J China. 2014; 94:3805-3808.

11. An H, Xu L, Chang Y, Zhu Y, Yang Y, Chen L, Lin Z, Xu J. $\mathrm{CXC}$ chemokine receptor 2 is associated with postoperative recurrence and survival of patients with non-metastatic clear-cell renal cell carcinoma. Eur J Cancer. 2015; 51:1953-1961.

12. Li L, Xu L, Yan J, Zhen Z, Ji Y, Liu C, Lau WY, Zheng L, $\mathrm{Xu}$ J. CXCR2-CXCL1 axis is correlated with neutrophil infiltration and predicts a poor prognosis in hepatocellular carcinoma. J Exp Clin Cancer Res. 2015; 34:129.

13. Hertzer KM, Donald GW, Hines OJ. CXCR2: a target for pancreatic cancer treatment? Expert Opin Ther Targets. 2013; 17:667-680.

14. Tierney JF, Stewart LA, Ghersi D, Burdett S, Sydes MR. Practical methods for incorporating summary time-to-event data into meta-analysis. Trials. 2007; 8:16.

15. Liang B, Zhao H, Che JB, Wang HJ, Shi GN. Overexpression of interleukin-8 receptor 2 (IL-8R2) indicates better prognosis in esophageal adenocarcinoma and squamous cell carcinoma procession. Med Onco. 2014; 31:89.

16. Sui $\mathrm{P}, \mathrm{Hu} \mathrm{P}$, Zhang $\mathrm{T}$, Zhang $\mathrm{X}$, Liu Q, Du J. High expression of CXCR-2 correlates with lymph node metastasis and predicts unfavorable prognosis in resected esophageal carcinoma. Med Oncol. 2014; 31:809.

17. Wang Z, Liu H, Shen Z, Wang X, Zhang H, Qin J, Xu J, Sun Y, Qin X. The prognostic value of CXC-chemokine receptor 2 (CXCR2) in gastric cancer patients. BMC Cancer. 2015; 15:766.

18. Yang SB, Han F, Wu JH, Zhao Z, Zhan W. Association between CXCR2 and IL-22BP expression indicate a poor outcome for gastric adenocarcinoma progression. Oncol Lett. 2016; 12:1477-1484.

19. Nishi T, Takeuchi H, Matsuda S, Ogura M, Kawakubo H, Fukuda K, Nakamura R, Takahashi T, Wada N, Saikawa Y, 
Omori T, Kitagawa Y. CXCR2 expression and postoperative complications affect long-term survival in patients with esophageal cancer. World J Surg Oncol. 2015; 13:232.

20. Michael P. Keane JABY, Strieter RM. Depletion of CXCR2 Inhibits Tumor Growth and Angiogenesis in a Murine Model of Lung Cancer. J Immunology. 2015; 172:2853-2860.

21. Gabellini C, Trisciuoglio D, Desideri M, Candiloro A, Ragazzoni Y, Orlandi A, Zupi G, Del Bufalo D. Functional activity of CXCL8 receptors, CXCR1 and CXCR2, on human malignant melanoma progression. Eur J Cancer. 2009; 45:2618-2627.

22. Ha H, Debnath B, Neamati N. Role of the CXCL8CXCR1/2 Axis in Cancer and Inflammatory Diseases. Theranostics. 2017; 7:1543-1588.

23. Schraufstatter IU, Chung J, Burger M. IL-8 activates endothelial cell CXCR1 and CXCR2 through Rho and Rac signaling pathways. Am J Physiol Lung Cell Mol Physiol. 2001; 280:1094-1103.

24. Venkatakrishnan G, Salgia R, Groopman JE. Chemokine receptors CXCR-1/2 activate mitogen-activated protein kinase via the epidermal growth factor receptor in ovarian cancer cells. J Biol Chem. 2000; 275:6868-6875.

25. Desurmont T, Skrypek N, Duhamel A, Jonckheere N, Millet G, Leteurtre E, Gosset P, Duchene B, Ramdane N, Hebbar M, Van Seuningen I, Pruvot FR, Huet G, et al. Overexpression of chemokine receptor CXCR2 and ligand CXCL7 in liver metastases from colon cancer is correlated to shorter disease-free and overall survival. Cancer Sci. 2015; 106:262-269.
26. Rezakhaniha B, Dormanesh B, Pirasteh H, Yahaghi E, Masoumi B, Ziari K, Rahmani O. Immunohistochemical distinction of metastases of renal cell carcinoma with molecular analysis of overexpression of the chemokines CXCR2 and CXCR3 as independent positive prognostic factors for the tumorigenesis. IUBMB Life. 2016; 68:629-633.

27. Sueoka H, Hirano T, Uda Y, Iimuro Y, Yamanaka J, Fujimoto J. Blockage of CXCR2 suppresses tumor growth of intrahepatic cholangiocellular carcinoma. Surgery. 2014; 155:640-649.

28. Yang G, Rosen DG, Liu G, Yang F, Guo X, Xiao X, Xue F, Mercado-Uribe I, Huang J, Lin SH, Mills GB, Liu J. CXCR2 Promotes Ovarian Cancer Growth through Dysregulated Cell Cycle, Diminished Apoptosis, and Enhanced Angiogenesis. Clin Cancer Res. 2010; 16:3875-3886.

29. Cheng WL, Wang CS, Huang YH, Tsai MM, Liang Y, Lin KH. Overexpression of CXCL1 and its receptor CXCR2 promote tumor invasion in gastric cancer. Ann Oncol. 2011; 22:2267-2276.

30. Stofas A, Levidou G, Piperi C, Adamopoulos C, Dalagiorgou G, Bamias A, Karadimou A, Lainakis GA, Papadoukakis S, Stravodimos K, Dimopoulos M, Patsouris E, Gakiopoulou H, et al. The role of CXCchemokine receptor CXCR2 and suppressor of cytokine signaling-3 (SOCS-3) in renal cell carcinoma. BMC Cancer. $2014 ; 14: 149$. 